\title{
EFEKTIVITAS BIRTH BALL EXERCISE PADA IBU BERSALIN KALA I TERHADAP LAMA KALA I FASE AKTIF DAN LAMA KALA II DI RUANG BERSALIN PUSKESMAS ARSO 3 KABUPATEN KEROOM PROVINSI PAPUA
}

\author{
Sri Wahyuni' ${ }^{1}$, Ika Wijayanti², Peny Wena Betsy Maran 3 \\ 1,2Dosen Jurusan Kebidanan Poltekkes Kemenkes Jayapura Prodi D4 Kebidanan Jayapura \\ ${ }^{3}$ Dosen Jurusan Kebidanan Poltekkes Kemenkes Jayapura Prodi D3 Kebidanan Biak \\ email : sriwahyunijayus@gmail.com
}

\begin{abstract}
ABSTRAK
Pendahuluan. Risiko persalinan lama pada ibu yaitu bisa mengalami perdarahan karena atoni uterus, laserasi jalan lahir, infeksi, syok dan kelelahan, sementara pada bayi terjadi peningkatan angka kematian bayi, penurunan APGAR skor, trauma dan infeksi. Birth Ball Excercise dilakukan dengan cara ibu bersalin kala I fase aktif duduk diatas Birth ball kemudian mengayunkan dan menggoyangkan panggul kearah depan dan ke belakang, sisi kanan kiri dan melingkar akan terasa lebih relaks dan mempermudah membukanya jalan lahir pada waktu persalinan sehingga diharapkan dapat mengurangi kejadian persalinan lama. Tujuan. Mengetahui efektivitas Birth Ball Excercise terhadap lama waktu persalinan kala I dan lama kala II di Ruang Bersalin Puskesmas Arso 3 Kabupaten Keroom. Metode. Penelitian ini merupakan penelitian kuantitatif dengan rancangan quasi experiment, yaitu post test only design. Penelitian dilakukan di Puskesmas Arso 3. Dengan Intervensi birthball ini diharapkan dapat membantu mempercepat proses persalinan. Responden terdiri dari 30 responden (15 kelompok perlakuan, 15 kelompok control). Hasil. Ada perbedaan lama waktu kala 1 pada ibu yang diberi perlakuan Birt ball Exercise dan yang tidak diberi perlakuan Birth Ball Excercise dengan $\mathrm{p}$ value $0,015<0,05$. Ada perbedaan lama waktu kala 2 pada ibu yang diberi perlakuan Birth Ball Excercise dan yang tidak diberi perlakuan Birth Ball Excercise dengan p value 0,032<0,05. Kesimpulan. Birth ball Exercise efektif dalam mempercepat lama kala I dan mempercepat lama kala II.
\end{abstract}

Kata Kunci: lama kala 1 fase aktif, lama kala 2, Birth ball exercise.

\section{ABSTRACK}

Introduction. The risk of prolonged labor for the mother is bleeding due to uterine atony, laceration of the birth canal, infection, shock and fatigue, while in infants there is an increase in infant mortality, decreased APGAR score, trauma and infection. Birth Ball Excercise is carried out by the mother during the first active phase of labor sitting on the birth ball then swinging and shaking the pelvis forward and backward, the right and left sides and the circle will feel more relaxed and make it easier to open the birth canal during labor so that it is expected to reduce the incidence of labor long. Purpose. To determine the effectiveness of Birth Ball Excercise on the length of time for labor for the first stage and the length for the second stage in 
the delivery room at Arso 3 Health Center, Keroom Regency. Methods. This study is a quantitative study with a quasi-experimental design, namely posttest only design. The study was conducted at Arso 3 Public Health Center, with this birthball intervention is expected to help speed up the labor process. Respondents consisted of 30 respondents (15 treatment groups, 15 control groups). Results. There was a difference in the duration of period 1 in mothers who were given the Birt ball Exercise treatment and those who were not given the Birth Ball Excercise treatment with a $p$ value of $0.015<0.05$. There was a difference in the length of time 2 for mothers who were given the Birth Ball Exercise and those who were not. given the Birth Ball Excellence treatment with $p$ value $0.032<0.05$. Conclusion. Birth ball Exercise is effective in accelerating on the length of time for labor for the first stage and the length for the second stage.

Keywords: Lengh of time First Stage, Lengh of time second Stage, Birth ball exercise

\section{PENDAHULUAN}

Persalinan merupakan proses yang fisiologis dan kejadian yang menakjubkan bagi seorang ibu. Penatalaksanaan oleh bidan yang terbaik serta dukungan yang terus-menerus dengan menghasilkan persalinan yang sehat dan memuaskan dapat memberikan pengalaman yang menyenangkan (Wiknjosastro, 2010).

Risiko persalinan lama pada ibu yaitu bisa mengalami perdarahan karena atonia uterus, laserasi jalan lahir, infeksi, syok dan kelelahan, sementara pada bayi terjadi peningkatan angka kematian bayi, penurunan APGAR (Appearance, Pulse, Grimace, Activity, Respiration) skor, trauma dan infeksi. Birth Ball dilakukan dengan cara mengayunkan dan menggoyangkan panggul ke arah depan dan ke belakang, sisi kanan kiri dan melingkar akan terasa lebih relaks dan mempermudah membukanya jalan lahir pada waktu persalinan sehingga diharapkan dapat mengurangi kejadian persalinan lama (Mathew, Nayak, and K. 2012).

Hasil Survei Penduduk Antar Sensus (SUPAS) 2015 menunjukkan Angka Kematian Ibu (AKI) sebesar 305 per 100.000 kelahiran hidup, masih sangat tinggi dibandingkan perkiraan Kementerian Kesehatan. Dalam Tujuan Pembangunan Berkelanjutan/Sustainable Development Goals (SDGs), target AKI adalah 70 per 100.000 kelahiran hidup pada tahun 2030. Untuk mencapai target tersebut diperlukan kerja keras, terlebih jika dibandingkan dengan beberapa negara ASEAN, AKI di Indonesia relatif masih sangat tinggi. AKI di negara-negara ASEAN rata-rata sebesar 40-60 per 100.000 kelahiran hidup. Bahkan, AKI di Singapura sebesar 2-3 per 
100.000 kelahiran hidup (Susiana, 2019). Jumlah kasus kematian ibu di Provinsi Papua pada tahun 2017 mengalami penurunan dari angka 575 per 100 ribu kelahiran hidup menjadi 380 per 100 ribu kelahiran hidup. Penurunan angka kematian ibu ini disebabkan 90 \% Puskesmas sudah ada di distrik (kecamatan) dan juga Program Quickwins yaitu Kartu Papua Sehat (KPS) yang sudah menjangkau seluruh Orang Asli Papua (OAP). Sementara penyebab angka kematian ibu di Papua antara lain karena perdarahan, infeksi, eklamsia dan lainnya baik yang terjadi pada masa kehamilan, persalinan, maupun nifas (Dinkes Propinsi Papua, 2018).

Permasalahan di Indonesia sendiri masih banyak ditemukan diantaranya adalah partus lama yang merupakan salah satu dari beberapa penyebab kematian ibu dan bayi baru lahir. Partus lama adalah partus yang lebih dari 24 jam. Pada proses persalinan melewati empat kala, pada kala satu dibagi ke dalam dua fase, yaitu fase laten dan fase aktif. Pada fase laten merupakan periode dari awal persalinan hingga titik ketika pembukaan mulai berjalan secara progresif. Fase aktif merupakan periode waktu awal dari kemajuan aktif pembukaan hingga pembukaan menjadi komplit (Varney, 2002).

Pada primipara lama persalinan pada kala satu mempunyai durasi yang lebih lama jika dibandingkan dengan multipara,. Namun, tidak semua persalinan alamiah akan berakhir sesuai dengan waktu normal. Faktor yang mempengaruhi persalinan menjadi lama yaitu kelainan jalan lahir, malpresentasi, kontraksi yang tidak adekuat, kehamilan kembar, dan anemia (Varney, 2007).

Partus lama menjadi salah satu penyebab meningkatnya mortalitas dan morbiditas pada ibu dan janin. Pada ibu dengan partus lama lebih berisiko terjadi perdarahan karena atonia uteri, robekan jalan lahir, infeksi, syok dan kelelahan, sedangkan pada janin dapat meningkatkan risiko trauma cerebral, asfiksia berat, infeksi dan cedera akibat tindakan intervensi yang sering dilakukan diantaranya adalah induksi oksitosin, vakum ekstraksi dan Sectio Caesar (SC) dan dapat dipastikan intervensi ini meningkatkan morbiditas ibu dan bayi (Oxon \& Forte, 2010). Dibutuhkan latihan mobilitas dari ibu untuk menjaga agar ligamen tetap longgar, rileks, dan bebas dari ketegangan sehingga lebih banyak ruang untuk bayi turun ke panggul sehingga lama 
waktu persalinan kala I dan kala II dapat diperpendek dengan melakukan senam/olah tubuh (Mathew, Nayak, and K. 2012).

Menurut Aprilia (2011), Birthball Exercise merupakan gerakan dengan menggoyangkan panggul ke sisi depan, belakang, sisi kiri dan kanan dengan menggunakan Birthball. Gerakan ini digunakan untuk mengurangi rasa kurang nyaman pada saat proses persalinan di mana gerakan yang dilakukan ini ternyata memberi banyak sekali manfaat diantaranya mengurangi nyeri dan mempercepat persalinan baik pada kala I maupun kala II (Wulandari and Wahyuni 2019). Hasil penelitian Zaky HN (2016) menunjukkan ada hubungan antara pelaksanaan birth ball exercise terhadap lamanya kala I. Dengan melakukan birth ball exercise mampu memperlancar proses persalinan khususnya pada kala I dan membantu ibu mengalami waktu persalinan kala I yang normal.

Berdasarkan survey di Puskesmas Arso 3 didapatkan data dalam dua bulan (bulan OktoberNovember 2019) yaitu angka kejadian persalinan normal sejumlah 40 kasus, persalinan lama yang diakhiri dengan tindakan merujuk sejumlah 14 kasus. Dari 10 kasus persalinan lama didapatkan 9 ibu mengalami persalinan dengan kala I > 14 jam (64,28\%) dan 5 ibu bersalin $(35,72 \%)$ dengan kala II $>2$ jam, untuk itu dibutuhkan penanganan untuk meminimalkan masalah tersebut. Bidan Ruang Bersalin Puskesmas Arso 3 sudah ada yang dilatih untuk gerakan Birth Ball Exercise.

Berdasarkan uraian latar belakang tersebut, maka peneliti tertarik untuk melakukan penelitian dengan judul "Efektivitas Birth ball Exercise Pada Ibu Bersalin Kala I Terhadap Lama Kala I dan Lama Kala II di Puskesmas Arso 3 Kabupaten Keroom”.

\section{TUJUAN}

Mengetahui efektivitas Birth Ball Excercise terhadap lama waktu persalinan Kala I dan lama Kala II di Ruang Bersalin Puskesmas Arso 3 Kabupaten Keroom.

\section{METODE PENELITIAN}

Penelitian ini merupakan penelitian kuantitatif dengan rancangan quasi experiment, yaitu post test only design. Populasi dalam penelitian ini adalah seluruh ibu bersalin multigravida kala I Ruang Bersalin Puskesmas Arso 3. Pengambilan subjek penelitian dilakukan secara non probability / non random sampling dengan metode consecutive sampling, yaitu setiap subjek 
yang memenuhi kriteria inklusif dimasukkan dalam penelitian sampai kurun waktu tertentu berdasarkan urutan kedatangan responden di tempat penelitian sampai memenuhi jumlah sampel.

Jumlah sampel pada penelitian ini yaitu $30 \mathrm{ibu}$ bersalin primigravida Kala I (15 pada kelompok intervensi dan 15 pada kelompok kontrol). Kriteria inklusi pada penelitian ini adalah ibu hamil normal dengan tidak memiliki komplikasi kehamilan (non-risiko), Kehamilan tunggal dengan presentasi kepala, Tinggi Fundus Uteri (TFU) tidak $>$ dari $40 \mathrm{~cm}$, Lingkar Lengan Atas (LILA) tidak $<$ dari 23,5 $\mathrm{cm}$ dan Tinggi badan $(\mathrm{TB})>150 \mathrm{~cm}$.

Kelompok intervensi pada penelitian ini yaitu kelompok responden yang difasilitasi untuk melakukan birth ball Excercise, sedangkan kelompok kontrol hanya dilakukan Asuhan Persalinan Normal(APN) sesuai standar APN tanpa dilakukan birthball Excercise selama Kala I fase aktif. Birth ball Excercise pada kelompok intervensi dilakukan setiap 1 jam sekali selama 20 menit dalam kala I fase aktif pembukaan $4 \mathrm{~cm}$ (saat kontraksi berlangsung) sesuai dengan prosedur penatalaksanaan birth ball Excercise. Penilaian kemajuan persalinan dilakukan 4 jam kemudian atau jika ada indikasi dengan menggunakan lembar observasi partograf.

\section{HASIL}

\section{Karakteristik Responden}

Karakteristik responden dalam penelitian ini adalah sebagai berikut:

Tabel 1. Karakteristik (umur, pendidikan, pekerjaan), status gizi, Tinggi Fundus Uteri (TFU) dan Berat Badan (BB) Bayi Lahir pada ibu bersalin yang Birth ball Excercise dan yang tidak dilakukan Birth ball Exercise

\begin{tabular}{lllllc}
\hline Variabel & $\begin{array}{l}\text { Kelompok } \\
\text { Perlakuan } \\
\text { Mean } \pm \text { SD }\end{array}$ & $\begin{array}{l}\text { Kelompok } \\
\text { Kontrol } \\
\text { Mean } \pm \text { SD }\end{array}$ & $\begin{array}{l}\text { Uji } \\
\text { Beda }\end{array}$ & \multicolumn{2}{c}{ Uji Correlation } \\
& $30,53 \pm 4,52$ & $27,47 \pm 4,47$ & $0,072^{1}$ & $0,296^{3}$ & 0,510 \\
& $38,53 \pm 1,152$ & $38,60 \pm 1,35$ & 0,884 & 0,227 & 0,959 \\
\hline Umur (tahun) & $32,13 \pm 2,669$ & $31,67 \pm 3,016$ & 0,657 & 0,421 & 0,775 \\
Umur Kehamilan (minggu) & $26 \pm 0,756$ & $25,8 \pm 1,265$ & 0,603 & 0,399 & 0,872 \\
TFU (cm) & $2900 \pm 354$ & $2893 \pm 273$ & 0,954 & 0,966 & 0,727 \\
LILA (cm) & & & & & \\
BB Bayi Baru lahir(gram) & & & & \\
Pendidikan & $7(46,7 \%)$ & $9(60 \%)$ & $0,464^{2}$ & 0,424 & 0,310 \\
$\quad$ 1. Dasar & $8(53,3 \%)$ & $6(40 \%)$ & & & \\
$\quad$ 2. Tinggi & & & & & \\
$\quad$ & & & &
\end{tabular}




\begin{tabular}{rlllll}
\hline Pekerjaan & & & & \\
1. Ibu rumah tangga & $7(46,7 \%)$ & $9(60 \%)$ & $0,632^{2}$ & 0,240 & 0,482 \\
2. Swasta & & & & \\
3. PNS & & & \\
& $4(26,7 \%)$ & $4(26,7 \%)$ & & \\
& $2(26,7 \%)$ & $2(13,3 \%)$ & & \\
\hline
\end{tabular}

Uji Beda :

${ }^{1}$ uji independent $t$ test

${ }^{2}$ chi square

Uji Correlatioan

${ }^{3} \mathrm{Uji}$ korelasi spearmen rank

Berdasarkan tabel 1 diatas didapatkan bahwa karakteristik responden pada kelompok perlakuan yang diberikan intervensi birth ball Excercise rata-rata berumur 30,53 tahun, umur kehamilan rata-rata 38,53 minggu, TFU rata-rata 32,13 cm, LILA rata-rata $26 \mathrm{~cm}$, Berat badan bayi baru lahir rata-rata 2900 gram, Pendidikan terbanyak adalah Pendidikan Tinggi 8(57,1\%), Pekerjaan terbanyak adalah ibu rumah tangga 7 (46,7\%). Sedangkan karakteristik responden pada kelompok kontrol yang tidak diberi birth ball Excercise rata-rata berumur 27,47 tahun, umur kehamilan rata-rata 38,6 minggu, TFU rata-rata 31,67 cm, LILA rata-rata 25,8 cm, BB bayi baru lahir rata-rata 2893 gram, Pendidikan terbanyak adalah Pendidikan dasar (60\%), pekerjaan terbanyak adalah ibu rumah tangga (60\%).

Hasil analisis correlation dari karakteristik umur, umur kehamilan, TFU, LILA, BB Bayi baru lahir, Pendidikan, pekerjaan terhadap lama waktu kala I dan lama waktu kala II didapatkan $p$ value $(0,966-0,227)>0,05$ sehingga dapat disimpulkan bahwa pada penelitian ini tidak ada hubungan antara karakteristik umur, umur kehamilan, TFU, LILA, BB Bayi Baru lahir, Pendidikan, Pekerjaan dengan lama waktu Kala I maupun kala II. Hasil analysis uji beda untuk umur, umur kehamilan, TFU, LILA, BB Bayi Baru lahir, Pendidikan, Pekerjaan antara kelompok perlakuan dan kelompok control $(0,9-0,07)>0,05$ yang artinya tidak ada perbedaan karakteristik antara kelompok perlakuan dan kelompok control. 
2. Efektivitas Birth ball Excercise terhadap lama waktu persalinan kala I fase aktif di Puskesmas Arso 3

Efektifitas Birth ball Excercise terhadap lama waktu persalinan kala I fase aktif di Puskesmas Arso 3 dapat dilihat pada tabel 2 berikut ini :

Tabel 2. Efektifitas Birth ball Excercise terhadap lama waktu persalinan kala I fase aktif di Puskesmas Arso 3

\begin{tabular}{|c|c|c|c|c|c|}
\hline \multirow[t]{3}{*}{ Kelompok } & \multicolumn{5}{|c|}{ Lama Persalinan Kala I } \\
\hline & \multirow{2}{*}{$\begin{array}{l}\text { Mean } \\
\text { (jam) }\end{array}$} & Standar & \multirow[t]{2}{*}{$\mathrm{T}$} & \multicolumn{2}{|c|}{ Independen $t$ test } \\
\hline & & Deviasi & & $\begin{array}{c}\text { Mean } \\
\text { deference }\end{array}$ & P value \\
\hline Kelompok control & 6 & 1.195 & 2605 & 1.133 & 0,015 \\
\hline $\begin{array}{l}\text { Kelompok perlakuan } \\
\text { (PRE) }\end{array}$ & 4,67 & 1.187 & & & \\
\hline
\end{tabular}

Berdasarkan tabel 2 diatas didapatkan bahwa rata rata lama Kala 1 pada kelompok control adalah 6 jam dan rata-rata lama Kala I kelompok perlakuan adalah 4,67 Jam. Berdasarkan hasil uji independen $t$ test didapatkan bahwa p value 0,015<0,05 yang artinya terdapat perbedaan lama waktu Kala 1 pada ibu yang diberi perlakuan Birth ball Excercise dan yang tidak diberi perlakuan Birth ball Excercise.

3. Efektivitas Birth ball Excercise terhadap lama waktu persalinan Kala II pada di Puskesmas Arso 3

Tabel 3. Efektifitas Birth ball Excercise terhadap lama waktu persalinan kala II di Puskesmas Arso 3

\begin{tabular}{|c|c|c|c|c|c|}
\hline \multirow[t]{3}{*}{ Kelompok } & \multicolumn{5}{|c|}{ Lama Persalinan Kala II } \\
\hline & \multirow{2}{*}{$\begin{array}{l}\text { Mean } \\
\text { (menit) }\end{array}$} & \multirow{2}{*}{$\begin{array}{l}\text { Standar } \\
\text { Deviasi }\end{array}$} & \multirow[t]{2}{*}{$\mathrm{T}$} & \multicolumn{2}{|c|}{ Independen $t$ test } \\
\hline & & & & $\begin{array}{c}\text { Mean } \\
\text { deference }\end{array}$ & P value \\
\hline Kelompok control & 43,3 & 16,762 & 2.262 & 12333 & 0,032 \\
\hline Kelompok perlakuan (PRE) & 31,00 & 12,845 & & & \\
\hline
\end{tabular}

Berdasarkan tabel 3 diatas didapatkan bahwa rata rata lama Kala II pada kelompok control adalah 43,3 menit dan rata-rata lama Kala II kelompok perlakuan adalah 31,00 menit. Berdasarkan hasil uji independen $t$ test didapatkan bahwa $\mathrm{p}$ value $0,032<0,05$ yang artinya 
terdapat perbedaan lama waktu Kala II pada ibu yang diberi perlakuan Birth ball Excercise dan yang tidak diberi perlakuan Birth ball Excercise.

\section{PEMBAHASAN}

1. Karakteristik responden

Karakteristik responden pada penelitian ini kelompok perlakuan rata-rata berumur 30,53 tahun, umur kehamilan rata-rata 38,53 minggu, TFU rata-rata 32,13 cm, LILA rata-rata 26 $\mathrm{cm}$, Berat badan bayi baru lahir rata-rata 2900 gram, pendidikan terbanyak adalah Pendidikan Tinggi 8(57,1\%), pekerjaan terbanyak adalah ibu rumah tangga 7 (46,7\%). Sedangkan karakteristik responden pada kelompok kontrol rata-rata berumur 27,47 tahun, umur kehamilan rata-rata 38,6 minggu, TFU rata-rata 31,67 cm, LILA rata-rata 25,8 cm, BB bayi baru lahir rata-rata 2893 gram, pendidikan terbanyak adalah pendidikan dasar (60\%), pekerjaan terbanyak adalah ibu rumah tangga (60\%). Hasil analisis correlation dari karakteristik umur, umur kehamilan, TFU, LILA, BB Bayi baru lahir, Pendidikan, pekerjaan terhadap lama waktu kala I dan lama waktu kala II didapatkan p value $(0,966-0,227)>0,05$ sehingga dapat disimpulkan bahwa pada penelitian ini tidak ada hubungan antara karakteristik umur, umur kehamilan, TFU, LILA, BB Bayi Baru lahir, Pendidikan, Pekerjaan, dengan lama waktu Kala I maupun kala II. Hasil analysis uji beda untuk umur, umur kehamilan, TFU, LILA, BB Bayi Baru lahir, Pendidikan, Pekerjaan antara kelompok perlakuan dan kelompok control $(0,9-0,07)>0,05$ yang artinya tidak ada perbedaan karakteristik antara kelompok perlakuan dan kelompok control.

Hasil penelitian ini sejalan dengan penelitian menurut Surtiningsih (2016) yang menyebutkan bahwa karakteristik dalam penelitian Birth ball Excercise yang meliputi umur, umur kehamilan, TFU, LILA, BB Bayi Baru lahir, Pendidikan, Pekerjaan tidak berhubungan dengan lama waktu Kala I maupun kala II. Hal ini didukung oleh teori menurut Varney (2007). Persalinan merupakan rangkaian proses yang berakhir dengan pengeluaran hasil konsepsi oleh ibu. Proses ini dimulai dengan kontraksi persalinan sejati, yang ditandai oleh perubahan progresif pada servik, dan diahiri dengan kelahiran plasenta. Proses dinamika dari persalinan meliputi empat faktor yang saling berkaitan dan mempengaruhi persalinan. Empat faktor tersebut adalah power, passage, passanger dan psikis ibu. Selain 4 faktor 
tersebut juga tidak kalah pentingnya faktor Penolong persalinan. Faktor-faktor tersebut dapat dipengaruhi oleh faktor-faktor lain dapat mempengaruhi proses persalinan antaralain umur, paritas, jarak persalinan, pengetahuan ibu yang dapat dilihat dari tingkat pendidikan Jika terdapat masalah pada salah satu faktor tersebut maka dapat menyebabkan kesulitan selama persalinan (Purwaningsih, 2010). Kriteria inkluasi Pada penelitian ini seluruh responden merupakan ibu bersalin primipara, rentang usia reproduksi yaitu 20-35 tahun, Tinggi Fundus Uteri tidak melebihi $40 \mathrm{~cm}$ sebagai antisipasi bayi besar, LILA $>23,5 \mathrm{~cm}$ untuk memastikan responden tidak menderita kekurangan energi kronis yang terkait dengan status gizi ibu. Hasil analisis Correlation dari karakteristik umur, umur kehamilan, TFU, pendidikan, pekerjaan LILA ibu dan Berat Badan Bayi Lahir terhadap lama waktu kala I dan lama waktu kala II didapatkan $\rho$-value $(0,9-0,07)>0,05$ sehingga dapat disimpulkan dalam penelitian ini tidak ada pengaruh variabel umur, umur kehamilan, TFU, pendidikan, pekerjaan LILA ibu dan Berat Badan Bayi Lahir.

Dari hasil uji beda didapatkan tidak ada perbedaan karakteristik antara kelompok perlakuan dengan kelompok kontrol karena $\mathrm{p}$ value $>0,05$ ( $\mathrm{P}$ value sesuai tabel 1 mulai dari 0,072-0,954) Sehingga bisa disimpulkan antara kelompok perlakuan dan kelompok kontrol hampir sama.

2. Efektivitas Birth ball Excercise terhadap lama waktu persalinan Kala I fase aktif di Puskesmas Arso 3

Berdasarkan tabel 2 diatas didapatkan bahwa rata rata lama Kala 1 pada kelompok control adalah 6 jam dan rata-rata lama kala I kelompok perlakuan adalah 4,67 Jam. Hal ini sesuai dengan teori bahwa apabila dilihat dari partograf fase aktif yang diawali dari pembukaan $4 \mathrm{~cm}$ sampai $10 \mathrm{~cm}$ normalnya adalah 6 jam atau 360 menit (Kemenkes, 2013).

Berdasarkan hasil uji independen $t$ test didapatkan bahwa $\mathrm{p}$ value $0,015<0,05$ yang artinya terdapat perbedaan lama waktu Kala 1 pada ibu yang diberi perlakuan Birth ball Excercise dan yang tidak diberi perlakuan Birth ball Excercise. Aprilia (2010) mengatakan bahwa pelvic rocking merupakan cara yang efektif untuk bersantai bagi tubuh bagian bawah khususnya daerah panggul. Teknik ini sering disarankan selama persalinan. Untuk 
meningkatkan relaksasi dan memungkinkan gaya gravitasi untuk membantu perajalanan bayi melalui jalan lahir. Sehingga memungkinkan kemajuan proses persalinan menjadi lebih cepat (Aprilia, 2011). Hal ini sejalan dengan penelitian Wulandari dan Wahyuni (2019) yang menyebutkan bahwa ada hubungan antara Birth ball Excercise dengan lama kala I persalinan dengan $\mathrm{p}$ value 0,007. Penelitian yang lain yang sejalan adalah penelitian menurut Surtiningsih (2018) yang menyebutkan bahwa efektifitas Birth Ball Excercise dalam memperpendek lama kala 1 dalam kategori sangat kuat.

3. Efektivitas Pelvic Rocking Exercises Terhadap Lama Waktu Persalinan Kala II pada di Puskesmas Arso 3

Berdasarkan tabel 3 diatas didapatkan bahwa rata rata lama Kala II pada kelompok control adalah 43,3 menit dan rata-rata lama Kala II kelompok perlakuan adalah 31,00 menit. Berdasarkan hasil uji independen t test didapatkan bahwa $\mathrm{p}$ value $0,032<0,05$ yang artinya terdapat perbedaan lama waktu Kala II pada ibu yang diberi perlakuan Birth ball Excercise dan yang tidak diberi perlakuan Birth ball Excercise. Hal ini sejalan dengan penelitian menurut Wulandari dan Wahyuni (2019) yang menyebutkan bahwa ada hubungan antara Birth ball Excercise dengan lama kala II persalinan. Penelitian lain yang sejalan dengan penelitian ini yang menyebutkan bahwa efektifitas Birth ball Excercise terhadap lama kala II adalah kuat (Surtiningsih, 2018).

Posisi Gerakan Birth ball Excercise dengan duduk pada bola persalinan akan memfasilitasi peningkatan diameter antro posterior panggul. Begitu juga posisi pelvic rocking dengan bersandar pada bola dan bergerak ke depan dan ke belakang akan membantu untuk memandu kepala janin ke dalam panggul. Posisi tegak meningkatkan kondisi janin melalui pasokan oksigen yang cukup sehingga dapat meminimalisir terjadinya gawat janin (Aprilia, 2011).

\section{SIMPULAN}

1. Birth ball Exercise efektif dalam mempercepat lama kala I dengan $\mathrm{p}$ value $0,015<0,05$. Rata-rata lama Kala I pada kelompok kontrol (tidak diberi perlakuan Birth Ball Exsersice ) adalah 6 
jam. sedangkan rata-rata lama Kala I pada kelompok perlakuan (diberi perlakuan Birth Ball Exsersice) adalah 4,67 jam .

2. Birth ball Exercise efektif dalam mempercepat lama kala II dengan $\mathrm{p}$ value $0,032<0,05$. Rata-rata lama Kala II pada kelompok kontrol (tidak diberi perlakuan Birth Ball Exsersice ) adalah 43,3 menit. sedangkan rata-rata lama Kala II pada kelompok perlakuan (diberi perlakuan Birth Ball Exsersice) adalah adalah 31,00 menit .

\section{DAFTAR PUSTAKA}

Aprilia, Yesi. 2010. Hipnostetri: Rileks, Nyaman, dan Aman Saat Hamil dan Melahirkan. Gagas Media, Jakarta.

Aprilia,Y.Ritchmond. 2011. Gentle Birth Melahirkan Tanpa Rasa Sakit. Jakarta:Gramedia Widiasarana Indonesia.

Dinas Kesehatan Provinsi Papua. 2018. Profil Kesehatan Provinsi Jawa Tengah tahun 2017. DINKES Provinsi Papua.

Kemenkes RI. 2013. Pelayanan Kesehatan Ibu Di Fasilitas Kesehatan Dasar Dan Rujukan. Jakarta.

Oxorn H, Forte WR. (2010). Ilmu Kebidanan; patologi \& fisiologi persalinan. Yogyakarta. Yayasan Essentia Medica (YEM)

Mathew, Albin, Sabitha Nayak, and Vandana K. 2012. "A Comparative Study on Effect of Ambulation and Birthing Ball on Maternal and Newborn Outcome Among Primigravida Mothers in Selected Hospitals in Mangalore." Journal of Health and Allied Sciences NU 02(02): 02-05.

Purwaningsih, Wahyu, dkk. 2010. Asuhan Keperawatan Maternitas. Yogyakarta : Nuha Medica.

SUPAS. 2015. Profil Penduduk Indonesia Hasil SUPAS 2015. diakses dari : https://www.bps.go.id/publication/2016/11/30/63daa471092bb2cb7c1fada6/profilpenduduk-indonesia-hasil-supas-2015.html

Surtiningsih, Surtiningsih. 2018. "Efektifitas Pelvic Rocking Exercises Terhadap Lama Waktu Persalinan Pada Ibu Primipara Di Puskesmas Wilayah Kabupaten Banjarnegara." Jurnal Keperawatan Soedirman 11(2): 117-129.

Susiana, Suli. 2019. ANGKA KEMATIAN IBU: FAKTOR PENYEBAB DAN UPAYA PENANGANANNYA. Info Singkat BIDANG KESEJAHTERAAN SOSIAL KAJIAN 
SINGKAT TERHADAP ISU AKTUAL DAN STRATEGIS, Pusat Penelitian Badan Keahlian DPR RI http://puslit.dpr.go.id ISSN 2088-2351

Varney, Hellen. 2007. Buku Ajar Asuhan Kebidanan. Jakarta. EGC.

Wulandari, Catur Leny, and Sri Wahyuni. 2019. "Efektivitas Pelvic Rocking Exercise Pada Ibu Bersalin Kala I Terhadap Kemajuan Dan Lama Persalinan.” Jurnal Ilmiah Keperawatan (9).http://research.unissula.ac.id/file/publikasi/210104087/9092Buku_Pelvic_ibu_Leni_Fix. pdf.

Wiknjosastro, Hanifa 2010. Ilmu Kebidanan. Yayasan Bina Pustaka Sarwono Prawirohardjo, Jakarta.

Zaky HN., Effect of pelvic rocking exercise using sitting position on birth ball during the first stage of labor on its progres, IOSR Journal of Nursing and Health Science, 2016 ; PP 1927.Mathew, Albin, Sabitha Nayak, and Vandana K. 2012. "A Comparative Study on Effect of Ambulation and Birthing Ball on Maternal and Newborn Outcome Among Primigravida Mothers in Selected Hospitals in Mangalore." Journal of Health and Allied Sciences NU 02(02): 02-05. 